\title{
AVALIAÇÃO DO POTENCIAL FUNGICIDA DE EXTRATOS ETANÓLICOS DE Senna alata CONTRA Monosporascus cannonballus
}

\author{
Evaluation of the fungicide potential of ethanolic extracts of Senna alata \\ against Monosporascus cannonballus
}

\author{
Marcelino Gevilbergue Viana ${ }^{1}$, Cynthia Cavalcanti de Albuquerque ${ }^{2}$, Erika Valente de Medeiros ${ }^{3}$, \\ Francisco Arnaldo Viana ${ }^{4}$, Kathia Maria Barbosa e Silva ${ }^{5}$
}

\begin{abstract}
RESUMO
Objetivou-se, neste trabalho, avaliar in vitro a atividade dos extratos alcoólicos de Senna alata (L.) Roxb. sobre Monosporascus cannonballus. $\mathrm{O}$ delineamento experimental foi inteiramente casualizado com esquema fatorial $3 \times 6+1$, sendo constituído por três partes da planta (caule, raiz e vagem), por seis concentrações $(0,25 ; 0,50 ; 50 ; 75 ; 250 ; 500 \mathrm{ppm})$ mais a testemunha, com quatro repetições por tratamento. As variáveis avaliadas foram: taxa de crescimento micelial (TCM), inibição do crescimento micelial (ICM) e área abaixo da curva do crescimento micelial (AACCM). A concentração de 500 ppm foi a mais eficiente, nas três partes vegetais avaliadas. O porcentual de inibição na referida concentração foi de $28,60 \%, 36,70 \%$ e $27,99 \%$ para caule, raiz e vagem respectivamente. Diante dos resultados, observa-se que os extratos de $S$. alata indicam um forte potencial de controle para o fungo Monosporascus cannonballus.
\end{abstract}

Termos para indexação: Fungicida vegetal, caule, raiz e vagem; Senna alata; Monosporascus cannonballus. ${ }^{1}$

\section{ABSTRACT}

The aim of this work was to evaluate the activity in vitro of the ethanolic extracts of Senna alata (L.) Roxb. over Monosporascus cannonballus. The experimental design was entirely randomized with factorial scheme $3 \times 7+1$, being constituted by three parts of the plant (root, stalk and green bean) for six different concentrations $(0.25 ; 0.50,50,75,250,500 \mathrm{ppm})$ plus the control, with four repeatitons for treatment. The available variables were: rate of micelial growth (TCM), inhibition of the growth micelial (ICM) and area under the curve of the growth micelial (AACCM). The concentration of $500 \mathrm{ppm}$ was the most efficient ,in the three available vegetal parts. The percentual of inhibition in the concentration was of $28.60 \%, 36.70 \%$ e $27.99 \%$ for stalk, root and green bean respectively. Before of the results, the extracts of $S$. alata display high control potential for Monosporascus cannonballus fungi.

Index terms: ethanolic extracts, vegetal fungicide, root, stalk, green bean, Senna alata; Monosporascus cannonballus.

(Recebido em 3 de maio de 2007 e aprovado em 14 de abril de 2008)

\section{INTRODUÇÃO}

A expansão da cultura do meloeiro (Cucumis melo L.) no Nordeste brasileiro, principalmente nos estados do Rio Grande do Norte e Ceará, trouxe consigo uma filosofia de cultivo intensivo e contínuo sem preocupação com rotações adequadas de culturas, o que contribuiu para o aumento de doenças radiculares. Dentre essas doenças evidencia-se uma síndrome denominada de "colapso do meloeiro" ou "morte súbita" que está se tornando um dos fatores limitantes à produção dessa olerícola em todo o mundo. Trata-se de uma complexa síndrome, ocasionada por diversos patógenos radiculares como fungos, bactérias e vírus, ocorrendo com certa freqüência o ataque conjunto de vários deles isolados ou em associação (SALES JUNIOR et al., 2003).

Monosporascus cannonballus Pollack \& Uecker destaca-se como um dos principais fitopatógenos envolvidos na complexa síndrome do colapso do meloeiro (BRUTON, 1998). Esse fungo juntamente com Acremonium cucurbitacearum Alfaro-García, W. Gams et J. García-Jiménez foram os principais responsáveis por perdas equivalentes a $40 \%$, em apenas 15 anos, em campos de produção de melão na Espanha (GARCÍA-JIMÉNEZ et al., 2000).

A presença do referido patógeno tem limitado a exploração comercial de meloeiro em regiões produtoras no Brasil e no mundo (SALES JUNIOR et al., 2003, 2004).

\footnotetext{
Biológo - Programa de Pós-Graduação em Ciência e Engenharia de Petróleo/PPGCEP - Núcleo de Petróleo e Gás - Universidade do Estado do Rio Grande do Norte/UERN - Campus Universitário Lagoa Nova - Cx. P. 1524 - 59072-970 - Natal, RN - bergvianna@hotmail.com

${ }^{2}$ Bióloga, Doutora em Botânica, Professora Adjunto II - Departamento de Ciências Biológicas/DECB - Universidade do Estado do Rio Grande do Norte/ UERN - Rua Professor Antônio Campos, s/n - Presidente Costa e Silva - 59610-090 - Mossoró, RN - cycavalcanti@gmail.com

${ }^{3}$ Bióloga, Doutora em Fitotecnia - Departamento de Ciências Vegetais - Laboratório de Agricultura Irrigada - Universidade Federal Rural do Semi Árido/ UFERSA - Br 110, Km 47 - Costa e Silva - 59628-720 - Mossoró, RN - evmbio@gmail.com

${ }^{4}$ Químico, Doutor em Química Orgânica, Professor Adjunto IV - Departamento de Química/DQ - Universidade do Estado do Rio Grande do Norte/UERN - Rua Professor Antônio Campos, s/n - Presidente Costa e Silva - 59610-090 - Mossoró, RN - arnaldo@yahoo.com.br

${ }^{5}$ Engenheira Agrônoma, Doutora em Fitotecnia, Professora Adjunto IV - Departamento de Ciências Biológicas/DECB - Universidade do Estado do Rio Grande do Norte/UERN - Rua Professor Antônio Campos, s/n - Presidente Costa e Silva - 59610-090 - Mossoró, RN - kmbsbarbosa@yahoo.com.br
} 
Os sintomas são facilmente observados nos períodos próximos à colheita, pois o sistema radicular é comprometido, chegando ao apodrecimento, e ao perder a função, a raiz não supre as necessidades hídricas da cultura, ocasionando a murcha generalizada. Ao final do cultivo, pode ser observado peritécio do fungo que apresenta um aspecto de pontos negros, redondos que caracterizam o nome do fungo (SALES JUNIOR et al., 2001, 2002), facilitando a identificação do agente causal da doença no campo.

Alternativas de controle como utilização de portaenxertos resistentes à $M$. cannonballus (EDELSTEIN et al., 1999), a solarização do solo, o controle biológico (SALES JUNIOR et al., 2007) e a busca por novas moléculas fungicidas eficientes vêm sendo bastante estudados (MEDEIROS et al., 2006a,b).

Com relação ao controle biológico, Trichoderma spp. vem sendo utilizado como agente de biocontrole de M. cannonballus, sendo capaz de atenuar a infecção (BRUTON, 1998). Esse fato é devido à sua capacidade competitiva, seja pelo rápido crescimento micelial ou ao antagonismo direto, envolvendo enrolamento e penetração de hifas, somado à secreção de antibióticos deletérios ao fitopatógeno (JEFFRIES \& YOUNG, 1994).

Em se tratando do controle químico, Cohen et al. (1999) estudando a eficiência de 29 fungicidas observaram que o mais eficiente para o controle de tal fungo foi o Fluazinam, seguido do Kresoxim-metílico. A substância Tiazolidina-2,4-diona, sintetizada em laboratório, também vem sendo eficiente no controle de isolados do Nordeste brasileiro, sendo uma molécula de alvo específico, pois não inibe o crescimento do fungo benéfico Trichoderma spp. (MEDEIROS et al., 2006a).

O uso desses produtos pode ter, em curto prazo, um efeito positivo para o produtor. No entanto, em longo prazo, além do surgimento de isolados fitopatogênicos resistentes às substâncias químicas utilizadas, os resultados para sociedade como um todo e para o meio ambiente podem se tornar negativos devido à poluição causada pelos resíduos. Nesse contexto, termos como: "agricultura alternativa" estimula a busca de novas medidas de controle (STANGARLIN et al., 1999).

Pesquisas mostraram que compostos naturais extraídos de plantas medicinais vêm substituindo produtos agrícolas, no controle de doenças de plantas (CASTELLANOS et al., 2001). Esses compostos naturais são obtidos do metabolismo secundário da planta, aparentemente sem atividade na mesma (DI STASI, 1996). Dentre as espécies com potencial antimicrobiano, Senna alata se destaca, devido ao grande número de estudos a cerca do seu potencial medicinal (IBRAHIM \& OSMAN, 1995; KHAN et al., 2001;
SOMCHIT et al., 2003) e pela sua abundância na região potiguar. A espécie S. alata (L.) Roxb., pertencente à família Fabaceae (APG, 1998) é provavelmente nativa do norte da América do Sul, sendo naturalizada e cultivada desde os Estados Unidos da América até a Argentina (IRWIN \& BARNEBY, citados por RODRIGUES et al., 2005).

$\mathrm{Na}$ agricultura, os extratos de $S$. alata podem se constituir como uma alternativa para inibição de vários microrganismos responsáveis por perdas elevadas de diversas culturas (CHOMNAWANG et al., 2005; IBRAHIM \& OSMAN, 1995; OWOYALE et al., 2005).

Tendo em vista a crescente busca por formas alternativas de controle de doenças de plantas e devido aos resultados positivos com relação à atividade antimicrobiana da espécie, objetivou-se, no presente trabalho, avaliar, in vitro, o potencial de inibição de crescimento do fitopatógeno $M$. cannonballus utilizando diferentes concentrações dos extratos etanólicos do caule, raiz e vagem de $S$. alata que ocorrem no nordeste brasileiro.

\section{MATERIALE MÉTODOS}

\section{Material vegetal e obtenção dos extratos}

O material vegetal de $S$. alata, constituído das partes do caule, raiz e vagem foi coletado no município de Rafael Fernandes - RN e o espécime testemunho foi incorporado ao acervo do Herbário Dárdaro de Andrade-Lima (MOSS), da Universidade Federal Rural do Semi-Árido (UFERSA, Mossoró-RN). Após a coleta, o material foi pesado e colocado para secar em estufa de circulação forçada a uma temperatura de $65^{\circ} \mathrm{C}$. Após a secagem, o material vegetal foi triturado até grau de pó semifino. Os extratos das diferentes partes do vegetal foram preparados por extração exaustiva com etanol (3 x $500 \mathrm{~mL})$ a frio. Após extração, os extratos etanólicos de $S$. alata foram concentrados em rotavapor sob pressão reduzida. As soluções estoques de cada parte da planta foram preparadas a partir dos extratos dissolvidos em etanol na concentração de 1000 ppm.

\section{Obtenção do isolado Monosporascus cannonballus}

O isolado fúngico $M$. cannonballus foi obtido pelo método rotineiro de plaqueamento (MENEZES \& SILVAHANLIN, 1997) a partir de plantas de meloeiro naturalmente infectadas que apresentaram sintomas de colapso de ramas, provenientes de fazendas produtoras de melão, localizadas no município de Mossoró-RN. Das raízes, foram retirados fragmentos superficiais de tecidos vegetais com sintomas de contaminação. Esses fragmentos passaram por desinfestação em álcool a $70 \%$ durante 1 minuto, hipoclorito de cálcio a $1,5 \%$ durante 2 minutos e três lavagens consecutivas com água destilada esterilizada. 
Os fragmentos de tecidos vegetais, após desinfestados, foram secos em papel de filtro, esterilizados e transferidos para placas de Petri, contendo o meio de cultura BDA (batata-dextrose-ágar), acrescido de 500 ppm de estreptomicina, as quais foram mantidas à $27^{\circ} \mathrm{C}$ durante quatro dias. Posteriormente, os pontos de isolamento foram repicados para cultivos puros, quando foi realizada a seleção de um isolado de $M$. cannonballus, cuja identificação foi confirmada por microscopia óptica.

Após a seleção, o isolado foi repicado em culturas puras e incubadas em estufa (B.O.D.) a $27^{\circ} \mathrm{C}$ e fotoperíodo de $12 \mathrm{~h}$ de alternância de luz.

\section{Atividade antifúngica dos extratos etanólico de Senna alata}

Discos de micélio do fungo $M$. cannonballus, com aproximadamente $6 \mathrm{~mm}$ de diâmetro, foram retirados de culturas com 15 dias e depositados no centro de uma placa de Petri contendo meio BDA, ao qual adicionou-se, individualmente, diferentes concentrações do extrato etanólico ativo de cada parte de $S$. alata. As concentrações avaliadas foram: 0,$25 ; 0,5 ; 50 ; 75 ; 250$ e 500 ppm, obtidas a partir de uma série de diluições da solução estoque de 1000 ppm. As placas de Petri foram incubadas à $27^{\circ} \mathrm{C}$ em B.O.D e o tratamento-controle foi constituído do meio BDA sem extrato.

$\mathrm{O}$ delineamento experimental utilizado foi do tipo inteiramente casualizado, distribuídos em esquema fatorial $3 \times 6+1$, sendo 3 partes da planta e 6 concentrações de extratos etanólicos mais a testemunha, com quatro repetições.

As avaliações foram realizadas diariamente através de medição do diâmetro das colônias (média de duas medidas perpendiculares), até o total crescimento do tratamento-controle. As variáveis analisadas foram taxa de crescimento micelial (TCM) em milímetro, porcentagem da inibição do crescimento micelial calculado pela fórmula de Abbott (1925): $\operatorname{ICM}(\%)=(\mathrm{T}-\mathrm{t}) * 100 / \mathrm{T}$, onde $\mathrm{T}$ é a testemunha; $\mathrm{t}$ o tratamento e área abaixo da curva de crescimento micelial (AACCM), utilizando a fórmula: AACCM = " $\left((y i+y i+1) / 2 . d_{t i}\right)$, onde $y_{i}$ e $y_{i+1}$ são os valores de crescimento da colônia observados em duas avaliações consecutivas e $\mathrm{d}_{\mathrm{ti}} \mathrm{o}$ intervalo entre as avaliações. Para efeito de análise, os dados originais da ICM foram transformados em arcsen raiz $(x+0,5 / 100)$ e submetidos à análise de variância e as médias comparadas pelo teste de Tukey, ao nível de 5\% de probabilidade. Com as médias dos dados brutos foram obtidas e selecionadas curvas de regressões, tendo as concentrações dos extratos como variável independente. Modelos exponenciais, logarítimo, quadrático e polinomiais foram testados, tendo sido selecionados com base no coeficiente de determinação $\left(\mathrm{R}^{2}\right)$ e no quadrado médio do resíduo (QMR). As análises foram realizadas pelo programa computacional Sistema para Análise de Variância SISVAR (FERREIRA, 2000).

\section{RESULTADOS E DISCUSSÃO}

O extrato etanólico de $S$. alata mostrou atividade para cada parte vegetal diante do controle micelial de $M$. cannonballus, agente causador do colapso do meloeiro, em todas as variáveis analisadas.

Houve interação significativa entre as concentrações e os extratos etanólicos de diferentes partes da planta. Os modelos polinomiais foram os que melhor se adequaram em descrever o comportamento das variáveis ICM, TCM e AACCM em função das concentrações (Figura 1.).

Para a variável inibição do crescimento micelial, houve interação significativa $(\mathrm{P}=0,05)$ entre as concentrações e as partes da planta. A concentração de 500 ppm foi a mais eficiente, nas três partes vegetais avaliadas. O porcentual de inibição na referida concentração foi de 28,6\%, 36,7\% e 27,99\% para caule, raiz e vagem, respectivamente.

Os modelos polinomiais que melhor descreveram o comportamento do extrato etanólico das três partes da planta de $S$. alata em diferentes concentrações, obtiveram coeficientes de determinação de 88\% (Caule), 97\% (Raiz) e 90\% (Vagem) (Figura 1.A).

Em relação à taxa de crescimento micelial, também houve interação significativa para os fatores. As médias foram submetidas à análise de regressão onde se obteve as equações polinomiais (Figura 1.B), as quais revelaram coeficientes de determinação que variaram de $88 \%$ (Caule) até $97 \%$ (Raiz).

O extrato etanólico da vagem foi menos eficiente que os demais extratos com relação ao crescimento micelial. Mesmo na concentração de 500 ppm, considerada a mais eficiente entre as doses avaliadas para as demais partes da planta, a taxa de crescimento micelial foi de $64,82 \mathrm{~mm}$, superior aos extratos de caule e raiz cuja inibição foi de 64,2 $\mathrm{mm}$ e 56,99 $\mathrm{mm}$ respectivamente.

Em relação à variável área abaixo da curva de crescimento micelial (AACCM), houve interação significativa entre os fatores. As equações polinomiais (Figura 1.C) melhor se ajustaram dentre as testadas, pois permitiram altos coeficientes de determinação para algumas partes da planta, tais como $76 \%$ para caule, $90 \%$ para raiz e $84 \%$ para vagem. Tal variável explica o comportamento do crescimento micelial do fungo durante todo o experimento e as curvas são parecidas com as da TCM devido a ambas se correlacionarem positivamente, já que se referem ao crescimento micelial. 

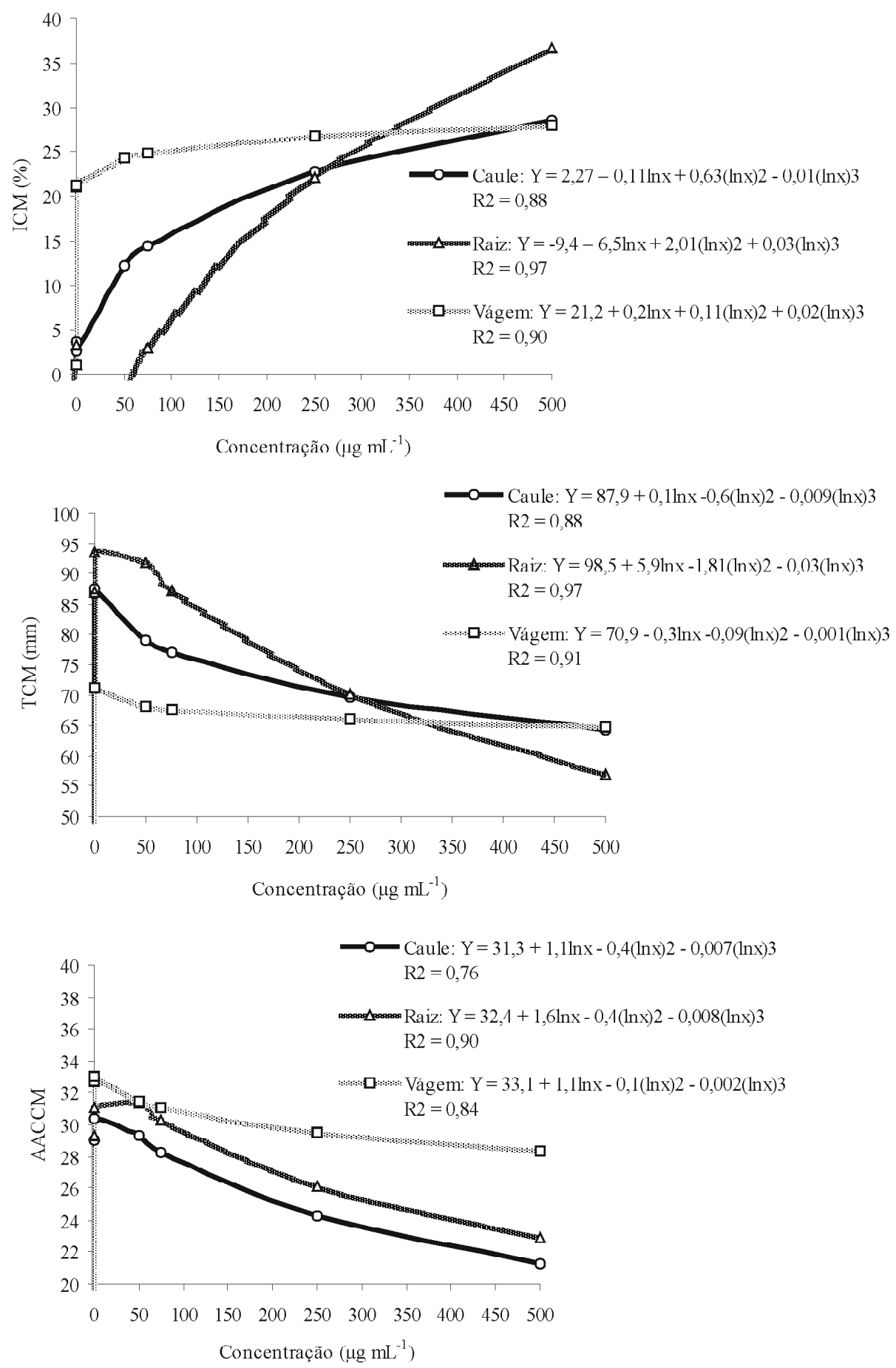

Figura 1 -A) Inibição do crescimento micelial (ICM), B) Taxa de crescimento micelial (TCM) e C) Área abaixo da curva de crescimento micelial (AACCM) de Monosporascus cannonballus em meio BDA, com diferentes concentrações do extrato etanólico de Senna alata. UERN, Mossoró-RN, 2006. 
Vários métodos de controle químico têm sido avaliados sobre $M$. cannonballus numa perspectiva de alcançar um controle, com ação eficiente e com rápidos resultados. Os extratos de $S$. alata demonstraram atividade de inibição sobre $M$. cannonballus estatisticamente similar a alguns produtos químicos avaliados em outros trabalhos, em diferentes concentrações. O extrato etanólico da raiz apresentou atividade sobre a inibição do crescimento micelial (ICM) na concentração de 500 ppm similar ao composto químico tiazolidina-2,4-diona, utilizado na concentração de 50 ppm (MEDEIROS et al., 2006b). Além desse composto, outros derivados de tiazolidina como phenilimino-tiazolidinas vêm sendo eficientes para outros fungos de importância agrícola como Phytophthora capsici L., Pyricularia oryzae C., Fusarium spp. e Rhizoctonia solani $\mathrm{K}$. (XU et al., 2004).

Em outros experimentos, alguns compostos químicos como flusufamid, paclobutrazol e oxycarboxin foram avaliados in vitro e também demonstraram uma taxa de inibição do crescimento micelial de M. cannonballus de cerca de 40,4\% para os três compostos, valor aproximado ao extrato etanólico da raiz de $S$. alata $(36,7 \%)$. Por outro lado, outros compostos como flutriafol, polyoxin AL, triadimenol e unicanazol não demonstraram o mesmo efeito sobre M. cannonballus (COHEN et al., 1999), refletindo a ineficiência de alguns produtos químicos.

Vale salientar que neste trabalho a intenção não foi comparar a eficiência do produto químico sintético com a do extrato de $S$. alata e sim, mostrar que produtos naturais com atividade antimicrobiana podem vir a substituir os produtos químicos sintéticos, no combate a microrganismos fitopatogênicos de cultura comercialmente importantes.

Trabalhos recentes revelaram o potencial dos extratos de $S$. alata na inibição de diversos microrganismos, tanto de bactérias quanto de fungos (CHOMNAWANG et al., 2005; OWOYALE et al., 2005). Variações na atividade antimicrobiana podem ocorrer entre espécies do mesmo gênero. Um exemplo dessa afirmação foi um trabalho realizado por Phongpaichit et al. (2004), os quais testaram extrato metanólico bruto de folhas de $S$. alata contra os fungos Microsporum gypseum e Trichophyton rubrum e verificaram que o mesmo foi mais eficiente que extrato semelhante de outras espécies do mesmo gênero. Segundo os autores, observações microscópicas revelaram que as hifas e macroconídios dos fungos tratados com o extrato foliar de S. alata apresentavam-se enrugados e colapsados, podendo-se inferir a essas características uma possível liberação do conteúdo celular. Trabalhos mais recentes confirmam a eficiência de extratos metanólicos de
S. alata contra fungos de diversas espécies, como: Microsporum canis; Blastomyces dermatitidis; Trichophyton mentagrophytes; Candida albicans e Aspergillus flavus (MAKINDE et al., 2007).

É importante enfatizar que a atividade pode se mostrar diferenciada devido à localização e influências ambientais, as quais as plantas estão submetidas, além de outros fatores como variação genética, utilização de diferentes métodos de extração, $\mathrm{pH}$ e a temperatura (RANGANATHAN \& BALAJEE, 2000). Obviamente, o uso de diferentes concentrações pode interferir na variação de resultados obtidos em diferentes experimentos (SOMCHIT et al., 2003) e vários trabalhos demonstraram a eficácia da utilização de concentrações mais elevadas do extrato das diferentes partes de $S$. alata, no controle de microorganismos (KHAN et al., 2001; RANGANATHAN \& BALAJEE, 2000; SOMCHIT et al., 2003). No entanto, igual enfoque deve ser dado à presença de metabólitos secundários na planta para explicar a atividade antimicrobiana. De acordo com a literatura, os compostos responsáveis pela atividade antimicrobiana de S. alata são os flavonóides glicosídeos e compostos antraquinônicos (ORDOÑEZ et al., 2004). Nos extratos aquoso e alcoólico foram identificados outros compostos secundários como taninos e quinonas, que são produzidos pela planta em respostas a algum tipo de estresse ou ataque microbiano (PÉREZ et al., 2005).

\section{CONCLUSÃO}

Assim, os extratos alcóolicos de S. alata apresentam-se como uma alternativa de controle para $M$. cannonballus, já que a taxa de inibição alcançada se aproximou ou foi mais eficiente que alguns produtos químicos utilizados com frequiência em campo. Com isso, sua aplicação em campo pode permitir um controle eficiente com um custo econômico muito baixo e, principalmente, sem prejudicar o meio ambiente, tendo em vista ser um produto natural e biodegradável. Por isso, futuros ensaios em casa de vegetação utilizando concentrações iguais ou superiores a 500 ppm serão necessários para avaliar melhor a atividade antifúngica de $S$. alata.

\section{AGRADECIMENTO}

Ao Dr José Iranildo Miranda de Melo pela caracterização taxonômica da espécie vegetal estudada neste trabalho; À Universidade Federal Rural do SemiÁrido (UFERSA) por ceder as suas instalações físicas; À Universidade do Estado do Rio Grande do Norte e ao CNPq pelo apoio financeiro. 


\section{REFERÊNCIAS BIBLIOGRÁFICAS}

ABBOTT, W. S. A method of computing the effectiveness of an insecticide. Journal of Economic Entomology, College Park, v. 18, p. 265-267, 1925.

ANGIOSPERM PHYLOGENY GROUP. An ordinal classification for the families of flowering plants. Plant Systematics and Evolution, v. 213, p. 259-287, 1998.

BRUTON, B. D. Soilborne diseases in Cucurbitaceae: pathogen virulence and host resistence. In: CUCURBITACEAE'98, 1998. Proceedings... [S.1.: s.n.], 1998. p. 143-166.

CASTELLANOS, P. P.; BISHOP, C.; VILLALOBOS, M. J. P. Antifungal activity of the essencial oil of flowerheads of garland chrysanthemum (Chrysanthemum coronarium) against agricultural pathogens. Phytochemistry, Oxford, v. 57, n. 1, p. 99-102, 2001.

COHEN, R.; PIVONIA, S.; SHTIENBERG, D.; EDELSTEIN, M.; RAZ, D.; GERSTL, Z.; KATAN, J. Efficacy of fluazinam in suppression of Monosporascus cannonballus, the causal agent of sudden wilt of melons. Plant Disease, Quebec, v. 83, n. 12, p. 1137-1141, 1999.

CHOMNAWANG, M. T.; SURASSMO, S.; NUKOOLKARN, V. S.; GRITSANAPAN, W. Antimicrobial effects of Thai medicinal plants against acne-inducing bactéria. Journal of Ethnopharmacology, Lausanne, v. 101, p. 330-333, 2005.

DI STASI, L. C. Química de produtos naturais: principais constituintes ativos. In: e ciência. [S.l.: s.n.], 1996. 111 p. Plantas medicinais: arte

EDELSTEIN, M.; COHEN, R.; BURGER, Y.; SHRIBER, S.; PIVONIA, S.; SHTIENBERG, D. Integrated management of sudden wilt in melons, caused by Monosporascus cannonballus, using grafting and reduced rates of methyl bromide.Plant Disease, Quebec, v. 83, n. 12, p. 1142-1145, 1999.

FERREIRA, D. F. Análises estatísticas por meio do Sisvar para Windows: versão 4.0. In: REUNIÃO ANUAL DA REGIÃO BRASILEIRA DA SOCIEDADE INTERNACIONAL DE BIOMETRIA, 45., 2000, São Carlos. Anais... São Carlos: UFSCar, 2000. p. 255-258.

GARCÍA-JIMÉNEZ, J.; ARMENGOL, J.; SALES JUNIOR, R.; JORDÁ, C.; BRUTON, B. D. Fungal pathogens associated whith melon collapse in Spain. EPPO Bulletin, v. 30, p. 169-173, 2000.

IBRAHIM, D.; OSMAN, H. Antimicrobial activity of Cassia alata from Malaysia. Journal of Ethnopharmacology, Lausanne, v. 45, n. 3, p. 51-156, 1995.

JEFFRIES, P.; YOUNG, T. W. K. Interfungal parasitic relationships. Cambridge: Cambridge University, 1994. 296 p.

KHAN, M. R.; KIHARA, M.; OMOLOSO, A. D. Antimicrobial activity of Cassia alata. Fitoterapia, v. 72, n. 5, p. 561-564, 2001.

MAKINDE, A. A.; IGOLI, J. O.; TA'AMA, L.; SHAIBU, S. J.; GARBA, A. Antimicrobial activity of Cassia alata. African Journal of Biotechnology, Pretoria, v. 6, n. 13, p. 1509-1510, 2007.

MEDEIROS, E. V.; ALBUQUERQUE, J. F. C.; MICHEREFF, S. J.; SALES JÚNIOR, R.; NUNES, G. H. S. Controle de Monosporascus cannonballus por tiazolidina-2,4-diona e efeito sobre o agente de controle biológico Trichoderma spp. Caatinga, v. 19, n. 1, p. 4450, 2006a.

MEDEIROS, E. V.; SALES JUNIOR, R.; MICHEREFF, S. J.; BARBOSA, M. R. Quantificação de ascósporos de Monosporascus cannonballus em solos não cultivados de Caatinga e em áreas de cultivo de melão do Rio Grande do Norte e Ceará. Fitopatologia Brasileira, Brasília, v. 31, p. $500-504,2006 b$.

MENEZES, M.; SILVA-HANLIN, D. M. W. Guia prático para fungos fitopatogênicos. Recife: UFRPE, 1997. 106 p.

ORDOÑEZ, M. G.; GOVÍN, E. S.; BLANCO, M. A. Actividad antimicrobiana de Senna alata L. Revista Cubana de Plantas Medicinais, v. 9, n. 1, 2004.

OWOYALE, J. A.; OLATUNJI, G. A.; OGUNTOYE, S. O. Antifungal and Antibacterial Activities of an Alcoholic Extract of Senna alata Leaves. Journal Applied Science Environmental, v. 9, n. 3, p. 105-107, 2005.

PERÉZ, Y. B.; JIMÉNEZ, M. E. H.; PULPEIRO, O. G. Caracterización y estudio fitoquímico de Cassia alata $\mathrm{L}$. Plant Med, v. 10, n. 2, 2005. 

PHONGPAICHIT, S.; PUJENJOB, N.;
RUKACHAISIRIKUL, V.; ONGSAKUL, M. Antifungal activity from leaf extracts of Cassia alata L., Cassia fistula L. and Cassia tora L. Songklanakarin. Journal of Science and Technology, London, v. 26, n. 5, p. 741-748, 2004.

RANGANATHAN, S.; BALAJEE, S. A. M. AntiCryptococcus activity of combination of extracts of Cassia alata and Ocimum sanctum. Mycoses, v. 43, n. 7/8, p. 299301, 2000.

RODRIGUES, R. S.; FLORES, A. S.; MIOTTO, S. T. S.; BAPTISTA, L. M. O gênero Senna (Leguminosae, Caesalpinoideae) no Rio Grande do Sul, Brasil. Acta Botanica Brasílica, Porto Alegre, v. 19, n. 1, p. 1-16, 2005.

SALES JUNIOR, R.; ARMENGOL, J.; VICENT, A.; GARCIA-JIMÉNEZ, J. Evaluación de daños en raíces de melón y sandía y frecuencia de aislamiento de Acremonium cucurbitacearum y Monosporascus cannonballus en una parcela afectada de colapso. Boletín Sanidad Vegetal Plagas, v. 27, p. 177-183, 2001.

SALES JUNIOR, R.; BELTRÁN, R.; VICENT, A.; ARMENGOL, J.; GARCÍA-JIMÉNEZ, J.; MEDEIROS, E. V. Controle biológico de Monosporascus cannonballus com Chaetomium. Fitopatologia Brasileira, Brasília, v. 32, p. 70-74, 2007.

SALES JUNIOR, R.; NASCIMENTO, I. J. B.; FREITAS, L. S.; BELTRÁN, R.; ARMENGOL, J.; VICENT, A.; GARCIA-
JIMÉNEZ, J. First report of Monosporascus cannonballus on melon in Brazil. Plant Disease, Quebec, v. 88, n. 1, p. 84, 2004.

SALES JUNIOR, R.; OLIVEIRA, O. F.; SENHOR, R. F.; ALVES, M. Z. Monosporascus cannonballus agente causal do colapso em plantas de melão no Rio Grande do Norte. Fitopatologia Brasileira, Brasília, v. 28, n. 5, p. 567, 2003.

SALES JUNIOR, R.; VICENT, A.; ARMENGOL, J.; GARCIA-JIMÉNEZ, J.; KOBORI, R. F. Comportamento de cultivares de meloeiro e melancia inoculados com Acremonium cucurbitacearum e Monosporascus cannonballus. Fitopatologia Brasileira, Brasília, v. 27, n. 2, p. 206-210, 2002.

SOMCHIT, M. N.; REEZAL, I.; NUR, I. E.; MUTALIB, A. R. In vitro antimicrobial activity of ethanol and water extracts of Cassia alata. Journal of Ethnopharmacology, Lausanne, v. 84, p. 1-4, 2003.

STANGARLIN, J. R.; SCHWAN-ESTRADA, K. R. F.; CRUZ, M. E. S.; NOZAKI, M. H. Plantas medicinais. Biotecnologia: Ciência e Desenvolvimento, Brasília, ano 2, n. 11, p. 16-21, 1999.

XU, X.; QUIAN, X.; LI, Z.; SONG, G.; CHEN, W. Synthesis and fungicidal activity of fluorinecontaining phenyliminothiazolidines derivative. Journal of Fluorine Chemistry, v. 125, p. 1159-1162, 2004. 